\title{
A retrospective study on the causes for evisceration at Tilganga Eye Centre
}

\author{
Limbu B ${ }^{1}$, Saiju $\mathbf{R}^{2}$, Ruit $\mathrm{S}^{3}$ \\ ${ }^{1}$ MD Resident, ${ }^{2}$ Assistant Professor, ${ }^{3}$ Professor, Tilganga Eye Centre, Kathmandu, Nepal
}

\begin{abstract}
Background: Evisceration is one of destructive surgery of eye after which a patient loses his hope of restoration of sight forever.

Aim and objectives: To identify the major causes of evisceration at a tertiary eye centre of Nepal.

Materials and methods: This is hospital based retrospective study of patients presented at Tilganga eye centre, Kathmandu, Nepal over a period of two years (10 Nov 2004 to 10 Nov 2006). Out of 2,31,976 total OPD patients, 71 patients who had evisceration with or without implant were selected and finally, only 67 patients record were enrolled for study as data were insufficient in the remaining records to fill up the study format. Data processing and analysis done using computer SPSS 11.5.

Results: A total of 67 cases, with age ranging from 1.5 years to 85 years, out of which 33 male and 34 were female. Evisceration was performed most commonly due to trauma and it's subsequent sequele in 37 cases $(55.2 \%$ of total cases), who were within the age group of $30-59$ years $(p=0.033)$ and predominantly male 25 cases $(p=0.001)$. Most of the patients presented from outside Kathmandu valley, with visual acuity of no perception of light.

Conclusion: Evisceration without implant was most common surgical procedure, with trauma being the leading cause for it and most of the trauma was seen in active, potential and young male patients. So prevention of ocular injuries together with early treatment protocol is best way to decrease the rate of evisceration due to ocular trauma. To prevent ocular injuries news paper, television and health education may play an important role.
\end{abstract}

Key words: Ocular trauma, destructive surgery, evisceration.

E visceration (evisceration bulbi) is a one of the destructive surgical procedure where by intraocular structure along with the cornea is excised leaving behind the sclera and surrounding structure intact.

Finally to cover the corneal area defect, sclera and the conjunctiva is closed in two different layers. Among the destructive surgery, evisceration is the most commonly performed surgery with or without the ocular implant throughout the world especially in developing countries where eye care infrastructure are inaccessible to the general population.

The first recorded evisceration was performed by James Bear in 1817, which was accidentally performed as there was expulsive haemorrhage when he was doing iridectomy for a patient of acute Glaucoma and that made him to remove the content of the globe. The first routine evisceration was performed by Noyes in 1874 and published a review of the evisceration procedure that he used in cases of severe ocular infection. Later in 1884, Mules developed a unique technique for evisceration where he used a hollow glass ball into the scleral cavity after removal of content of globe and cornea $a^{1,2,3}$.

The World Health Organization (WHO) program for prevention of blindness estimates that 55 million eye injuries occur globally each year. Of these, 750000 require hospitalization and approximately 200000 are open globe injuries. The prevalence of blindness $(<3 / 60)$ as a result of injury is about 1.6 million and there are 19 million with visual impairment ${ }^{4}$. The economic cost for treating the patients with trauma is tremendenous accounting for US\$ 5 million and a loss of 60 work - years according to a study conducted in emergency department(USA) for a period of six month ${ }^{5}$.

Ocular trauma is a global health problem leading to one of the major cause of mortality, morbidity and disability of human life. Although ocular trauma is preventable

Correspondence

Dr. Ben Limbu, MD Resident

Tilganga Eye Centre

E-mail: ben_limbu007@yahoo.com 
unfortunately greater effort and resources are being invested in the clinical and surgical management of trauma than its prevention ${ }^{6}$.

A population based national blindness survey of Nepal (1981) found a blindness prevalence rate of $0.84 \%$, with trauma responsible for $7.9 \%$ of monocular blindness. In Nepal, "corneal trauma and ulceration" is the second most common cause of monocular blindness after cataract. Ocular trauma had significant impact for blinding eyes diseases if not treated in time. Superficial corneal trauma sustained specifically in agricultural countries such as Nepal often leads to rapid progression of corneal ulceration and visual loss , $, 7,8,9^{\text {. }}$.

\section{Materials and methods}

This is hospital based retrospective study of patients presented at Tilganga eye centre, Kathmandu, Nepal over a period of two years (10 Nov 2004 to 10 Nov 2006). Out of 2,31,976 total OPD patients, 71 patients who had evisceration with or without implant were selected but among them only 67 patients record were enrolled for study as data were insufficient in the remaining records to fill up the study format. Out of 67 cases, with age ranging from 1.5 years to 85 years, there were 33 male whereas 34 were female. Demographic data, site of trauma, cause for operation, operated eye, and types of anesthesia used were entered into a computer programme SPSS 11.6.

Trauma and its sequel is considered in those eviscerated patients who had loss of vision due to trauma either recent or in the past but presented now either seeking cosmetic or therapeutic reason like painful blind eye where vision loss is clearly due to trauma. In patients who underwent evisceration as a consequence of initial ocular surgeries were considered as post operative complications. However the patients who had evisceration without prior history of trauma or surgeries were recorded as endogenous endophthalmitis. Painful blind eye because of glaucoma and its treatment were categorized under glaucoma and its sequel. Non traumatic corneal ulcer that underwent evisceration either due to perforation or extension of the disease into the eye, were classified as corneal ulcer related. Similarly those patients who don't fit to above criteria were classified as others. Surgeries were further classified as either evisceration or evisceration with implant; Operated eyes were recorded as either right, left or both. Similarly anesthesia was noted as either under local anesthesia that include either peribulbar or retrobulbar and the other as general anesthesia. Ethnic group was classified as Indoraryan, Tibetoburman and Others. Finally, data were analyzed using computer based program.

\section{Statistical analysis}

A two sample t test was used to examine differences in mean values between cases and controls. A $P$ value of 0.05 or less was considered as being statistically significant.

\section{Results}

Out of 67 cases trauma and its subsequent sequel accounting for $55.2 \%$ (37 cases) was a leading cause for evisceration with or without implant. Among all majorities of the patients $81.1 \%$ (30 cases) had trauma at the home or at the field while doing agricultural work. Most vulnerable age group in patients who underwent evisceration because of trauma and its sequel was 30 - 59 years $(P=0.033)$ and significantly high number of male $(25$ cases $)$ population $(P=0.001)$.

Overall, out of 67 patients, 63 (94\%) patients had evisceration under local anesthesia, $43(64.2 \%)$ patients had evisceration without implant and frequently operated eye was right eye 38 cases $(56.7 \%)$.

There was high number of patients who had undergone evisceration from outside Kathmandu valley in comparison to patients from valley (55 Vs 12).

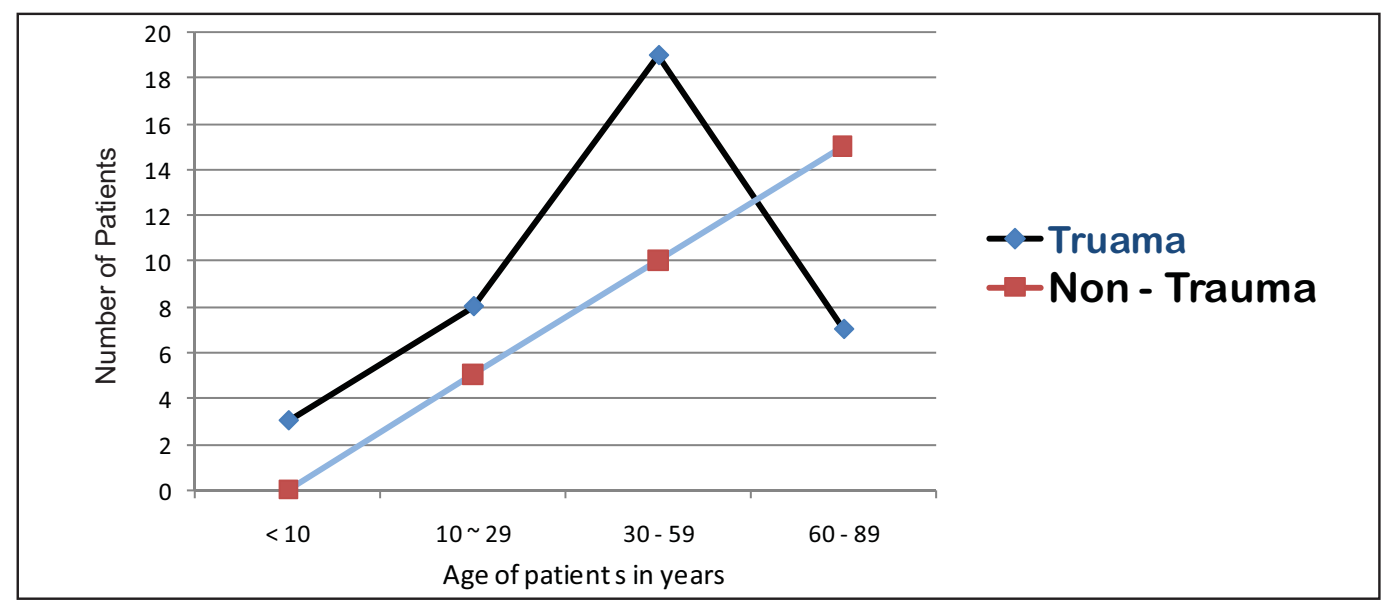

Fig 1: Relation of age with the number of eviscerated eyes in term of trauma vs. non trauma cases 
Table 1: Clinical Characteristics of study population

\begin{tabular}{|c|l|c|c|}
\hline S. No. & Characteristic & Number(n) & Percent \\
\hline \multirow{5}{*}{1.} & Ethnicity & & \\
& IndoAryan & 38 & 56.7 \\
& Tibetoburman & 23 & 34.3 \\
& Other & 6 & 9 \\
\hline & Age & 3 & 4.47 \\
2. & $<10$ & 13 & 19.40 \\
& $10-29$ & 29 & 43.28 \\
& $30-59$ & 22 & 32.83 \\
\hline \multirow{5}{*}{3.} & $60-89$ & & 49.3 \\
& Sex & 33 & 50.7 \\
\hline \multirow{5}{*}{4.} & Male & 34 & 64.2 \\
& Types of Surgery & & 35.8 \\
\hline \multirow{5}{*}{5.} & Evisceration & 43 & 94 \\
& Anaesthesia & 24 & 6 \\
\hline \multirow{3}{*}{6.} & Local anesthesia & & \\
& General anesthesia & 63 & 56.7 \\
& Operated Eye & 4 & 43.3 \\
\hline
\end{tabular}

Table 2: Sites of ocular injury

\begin{tabular}{|c|l|c|c|}
\hline S.No. & Site of Trauma & Number(n) & Percent \\
\hline 1. & Home/Agriculture field & 30 & 81.1 \\
\hline 2. & Industrial /Construction area & 2 & 5.4 \\
\hline 3. & Others & 5 & 13.5 \\
\hline
\end{tabular}

Table 3: Clinical diagnosis of patients who underwent evisceration

\begin{tabular}{|c|l|c|c|}
\hline S. No. & Clinical Diagnosis & Number (n) & Percent \\
\hline 1. & Trauma and its' sequele & 37 & 55.2 \\
\hline 2. & Corneal Ulcer related & 12 & 17.9 \\
\hline 3. & Others & 10 & 14.9 \\
\hline 4. & Post Operative Complications & 3 & 4.5 \\
\hline 5. & Endogenous Ophthalmitis & 3 & 4.5 \\
\hline 6. & Glaucoma and sequele & 2 & 3 \\
\hline
\end{tabular}

\section{Discussion}

When medical and surgical treatment fails to save the eyes from ocular disease that discomfort or alarm human lifestyle or which disfigure the eyes then the role of destructive surgery is clearly indicated. In our study we have analyzed only the cases that have under gone evisceration with or without implant. Ocular trauma and its sequel (37 cases; 55.2\%) is the major cause for evisceration that we have found. Though ocular trauma is preventable, it remained a global challenge to combat and decrease the blindness that is due to trauma even in $21^{\text {st }}$ century especially in developing countries like Nepal. Ocular trauma and its subsequent monocular blinding effect have been largely mentioned in different countries around the world ${ }^{4-20}$. But unfortunately none of the study focused upon the irreversible blindness that occurs with trauma, at the same time previous studies have compared the traumatic blindness with that of cataract blindness which is totally arguable. At this 
moment global concern on blinding ocular injuries is demanded. Our study result revealed most common site of the trauma being home $\mathrm{e}^{8,10,11}$ and agricultural filed. Prevalence of ocular trauma that needs evisceration increases with increasing age most common being young adults and majority are male ${ }^{14}$ this explains that trauma mainly affects a large number of active and energetic peoples of nation which can be easily prevented by public awareness. In contrast to our result, one study showed equal risk factor for both $\operatorname{sex}^{19}$ in trauma patients who needed evisceration and the other study showed children at greater risk and decreasing risk for the young adult ${ }^{12}$ for trauma.

Indication for evisceration have been reported from $10.7 \%-28 \%$ in previous literatures ${ }^{10,13,14,18}$. But in our study, there was high percentage $(55.2 \%)$ of ocular trauma \& its sequel that have resulted into evisceration, this might be because, other study didn't include the late trauma sequel in their study. On the other hand possibilities may include poverty, poor literacy, lack of knowledge, remote areas in the country without eye care facility, cultural and traditional beliefs together with unsafe working environment in our community might have resulted a positive influence for high percentage of cases.

The cause for evisceration remains one of the crucial questions as we know that once the surgery like evisceration is done, the hope for the vision to recover is obviously absent. So out of these curiosities we did this project and we found that ocular trauma is one of the leading causes for evisceration in our 67 cases of evisceration.

Early treatment seeking behavior of the patients should be motivated and traditional belief and treatment should be discouraged. At the same time it is important that surgeon should realize that the evisceration leads to not only visual loss to the patients but it can also significantly add economical burden. Moreover surgeon should also consider about the social and psychological factors and subsequently counsel patients and their family members before surgery.

\section{Conclusion}

Prevention is better than cure, if we can make population aware about the trauma and its impact this will help to decrease the blindness related to trauma. Prevention of injury may begin with finding the risk factors to define the problem. Moreover, changing behavior and adopting preventive measures often requires expanded community and government involvement. The media, newspapers, radio and television are extremely important in creating awareness of the problem in community.

\section{Acknowledgements}

The authors are grateful to all the staffs of Tilganga. Special thanks goes to Mr. Saroj Dhakal, Om Bdr Magar and Surya KC for their continuous support during searching of patients card from record store.

\section{References}

1. Meltzer MA, Schaefer DP, Della Rocca RC. Evisceration. Ophthalmic plastic and reconstructive surgery. Mosby ;1987; Vol. 2: 1300- 1307.

2. Fox SA. Enucleation and allied procedures. Ophthalmic Plastic Surgery. 5th Ed. New York: Grune and Stratton; 1976; 549 - 550.

3. Tanenbaum M. Enucleation, Evisceration and Exenteration. Ophthalmology. 2nd Ed. Reprint New Delhi, India: Elsevier; 2004. P. 752-60.

4. Negrel AD, Thylefors B. The global impact of eye injuries. Ophthalmic Epidemiology. 1998;5;143-69.

5. Alfanso EC, Arieta C, Bird AC, Blankenship $\mathrm{G}$ W, et al. Ocular trauma epidemiology and prevention. In: American Academy of Ophthalmology. International Ophthalmology. United State of America: American Academy of Ophthalmology; 2004 -2005. P. 121-34.

6. Upadhyay MD, Karmacharya PC, Koirala S, et al. Epidemiologic characteristics, predisposing factors, and etiologic diagnosis of corneal ulceration in Nepal. Am J Ophthalmol. 1991;111:92-9.

7. Brilliant LB, Pokhrel RP, Grasset NC, et al. Epidemiology of blindness in Nepal. Bull World Health Organ. 1985;63:375-86.

8. Upadhyay MP, Karmacharya PC, Koirala S, Shah DN, Shakya S, Shrestha JK, et al. The Bhaktapur eye study: ocular trauma and antibiotic prophylaxis for the prevention of corneal ulceration in Nepal. Br J Ophthalmol. 2001;85:388-92.

9. Khatry SK, Lewis AE, Schein OD, Thapa MD, Pradhan EK, Katz J. The epidemiology of ocular trauma in rural Nepal. Br J of Ophthalmol. 2004;88:456-60.

10. MacEwen CJ, Baines PS, Desai P. Eye injuries in children: the current picture. Br J Ophthalmol 1999;83:933-6.

11. Desai P, MacEwen CJ, Baines P, Minassian D. C. Incidence of cases of ocular trauma admitted to hospital and incidence of blinding outcome. British Journal of Ophthalmology 1996;80:592-6. 
12. Gerald M, Tyler AH, Aiyuan X, and Cynthia O. Trends in Eye Injury in the United States, 1992-2001. Investigative Ophthalmology and Visual Science. 2006;47:521-7.

13. Ozgur OR, Akcay L and Dogan OK. Primary Implant Placement With Evisceration in Patients With Endophthalmitis. Am J of Ophthalmol. 2005;139:333-4.

14. Chaudhary IA, Alkuraya HS, Shamsi FA, Elzaridi E,. Riley FC. Current Indications and Resultant Complications of Evisceration. Ophthalmic Epidemiology. 2007;14:93-7.

15. Viswanathan P, Sagoo MS, Olver JM. UK national survey of enucleation, evisceration and orbital implant trends. Br J Ophthalmol. 2007;91:616-9.

16. Essex RW, Qing MB, Patrick GPC and Allen PJ. Posttraumatic Endophthalmitis. Ophthalmology. 2005 Oct;112(10);1845-6.
17. Wong TY, Tielsch JM. A population-based study on the incidence of severe ocular trauma in Singapore. Am J Ophthalmol. 1999;128:34551.

18. Genevois O, Millet P, Retout A, Quintyn JC. Comparison after 10 years of two 100patient cohorts operated on for eviscerations or enucleations. Eur J Ophthalmol. 2004 SepOct;14(5):363-8.

19. Bal A, Mohan H, Chabbra S, Sood S. Causes of enucleation in Northern India (1995-2005). Eur J Ophthalmol. 2007 Jul-Aug;17(4):638-41.

20. Tawfik and Hamida B. Evisceration with Primary Implant Placement in Patients with Endophthalmitis. Ophthalmology. 2007 Jun;114(6):1100-3. 